\title{
AKTIVITAS REPELLENT FORMULASI SEDIAAN SPRAY KOMBINASI MINYAK ATSIRI SERAI (Cymbopogon winterianus), DAUN KEMANGI (Ocimum basilicum) DAN NILAM (Pogostemon cablin) BESERTA UJI PREFERENSINYA
}

\author{
Faikah Dyah Utami*, Arif Budi Setianto, Sapto Yuliani \\ Program Studi Farmasi, Fakultas Farmasi \\ Universitas Ahmad Dahlan \\ *Email: faikahdyah@gmail.com \\ Artikel diterima: 18 November 2020; Disetujui: 27 Februari 2021 \\ DOI: https://doi.org/10.36387/jiis.v6i1.631
}

\begin{abstract}
ABSTRAK
Tanaman yang berpotensi sebagai anti nyamuk, salah satunya adalah tanaman yang mengandung minyak atsiri, Serai, Kemangi dan Nilam. Namun ketiganya mengandung minyak atsiri yang kualitas berbeda. Sebagai upaya untuk mempermudah dalam penggunaan, penelitian ini akan membuat suatu sediaan berupa spray repellent dengan kombinasi bahan aktif dari minyak atsiri serai, kemangi dan nilam. Tujuan dari kombinasi minyak atsiri serai, kemangi dan nilam adalah untuk melihat efek sinergisme ke tiga minyak atsiri setelah di kombinasikan. Metode penelitian yang dilakukan meliputi pembuatan spray repellent dengan menggunakan Minyak atsiri Serai, Kemangi, Nilam masingmasing 0,1 ml (konsenterasi 5\%), 0,2 ml (konsentrasi 10\%), 0,3ml (konsentrasi 15 $\%$ ) dan bahan tambahanya Propilen glikol $1 \mathrm{ml}$ dan Etanol $96 \% 5 \mathrm{ml}$ yang berfungsi sebagai pelarut. Percobaan ini menggunakan lima perlakuan yaitu: Kontrol negatif $(\mathrm{Kn})$, Formula A $(0,1 \mathrm{ml})$, Formula B $(0,2 \mathrm{ml})$, Formula C $(0,3 \mathrm{ml})$, dan Kontrol Positif (Kp). Parameter yang diuji meliputi pengujian $\mathrm{pH}$, patch test, organoleptis, bobot jenis, kestabilan emulsi, preferensi dan prosentase daya proteksi. Pengujian daya proteksi yang diulang sebanyak 10 kali dari masingmasing perlakuan selama pengamatan 6 jam (0-1jam, 1-2jam, 2-3jam, 3-4jam, 45jam dan 5-6jam). Data yang diperoleh dianaliasis Uji Fisher-Test taraf $5 \%$, apabila uji $\mathrm{F}$ menunjukkan pengaruh nyata, maka dilanjutkan uji Beda Nyata terkecil (BNT) dalam taraf 5\%. Dari hasil penelitian, menunjukkan bahwa bahwa perlakuan repellent spray yang terbaik adalah pada formula B konsenterasi 10\%( $0,2 \mathrm{ml}$ ), karena karena beberapa parameter yang diamati menunjukan bahwa konsentrasi $10 \%(0,2 \mathrm{ml})$ itu tidak berbeda dengan konsentrasi $15 \%(0,3 \mathrm{ml})$, akan tetapi lebih baik dari konsenterasi $5 \%$.
\end{abstract}

Kata kunci: Aedes Aegepti, Kemangi, Nilam, Serai, Spray, Repellent

\section{ABSTRACT}

Plants that have the potential to act as mosquito repellents, one of which is plants that contain essential oils, lemongrass, basil and patchouli. all three contain essential oils different qualities. As an effort to make it easier to use, this research 
Jurnal Ilmiah Ibnu Sina, 6(1), Maret 2021, 87-97

p-ISSN: 2502-647X; e-ISSN: 2503-1902

will make a spray repellent with a combination of active ingredients from essential oils of lemongrass, basil and patchouli. Purpose of the combination of lemongrass, basil and patchouli essential oils is sight the synergistic effect of the three essential oils after they are combined. Research methodology includes making a spray repellent using essential oils of lemongrass, basil, patchouli, respectively concentration $0.1 \mathrm{ml}(5 \%), 0.2 \mathrm{ml}(10 \%), 0.3 \mathrm{ml}(15 \%)$ and other ingredients. He added $1 \mathrm{ml}$ of Propylene glycol and $5 \mathrm{ml}$ of $96 \%$ Ethanol which functioned as a solvent. Experiment used five treatments : Negative control (Kn), Formula A (0.1ml), B (0.2ml), C (0.3ml), and Positive Control (Kp). Parameters tested included $\mathrm{pH}$ testing, patch test, organoleptic, specific gravity, emulsion stability, preference. The protective power test repeated 10 times from each treatment for 6 hours of observation. data obtained were analyzed the Fisher-Test at $5 \%$ level, if the F test showed a significant effect, then the smallest significant difference (LSD) test was continued at the 5\% level. Results showed the best repellent spray treatment was formula B with concentration of $10 \%(0.2 \mathrm{ml})$, because the parameters observed showed that the concentration of $10 \%(0.2 \mathrm{ml})$ was not different from the concentration of 15\%. $(0.3 \mathrm{ml})$, but its better $5 \%$ concentration.

Key words: Aedes aegepty, basil, patchouli, lemongrass, spray, repellent

\section{PENDAHULUAN}

Penyakit demam berdarah dengue (DBD), filariasis (penyakit kaki gajah). Indonesia dan Thailand merupakan prevelensi demam berdarah yang cukup tinggi. (Irwan, 2019). Vektor utama dari demam berdarah dengue adalah nyamuk Aedes aegypti dan Aedes albopictus yang menggigit manusia. Bahaya dari demam berdarah dengue karena belum adanya vaksin penyembuhnya oleh karena itu perlu adanya pengendalian vektor penyakit demam berdarah, beberapa cara dilakukan salah satunya secara kimiawi seperti Menggunakan bahan kimia (insektisida) dengan formulasi spray (pengasapan), dust (bubuk), aerosol (semprotan). Cara ini memerlukan dana yang tidak sedikit serta mempunyai dampak negatif terhadap lingkungan. Minyak atsiri merupakan zat yang memberikan aroma pada tumbuhan dengan karakteristik tertentu. Saat ini, minyak atsiri telah digunakan sebagai parfum, kosmetik, bahan tambahan makanan dan obat. Serai dapat menghasilkan sensasi kehangatan ringan yang mengurangi nyeri otot dan sendi (Sulaswatty, 2019), minyak atsiri kemangi mengandung senyawa flavonoid dan saponin (Susanto, 2013) saponin dapat 
Jurnal Ilmiah Ibnu Sina, 6(1), Maret 2021, 87-97

p-ISSN: 2502-647X; e-ISSN: 2503-1902

bersifat larvasida dengan menurunkan tekanan permukaan selaput mukosa traktus digestivus larva sehingga dinding traktus menjadi korosif, flavonoid senyawa yang bersifat toksik terhadap seranggga Selain itu flavonoid juga mampu menghambat pertumbuhan larva. sedangkan minyak atsiri nilam dimanfaatkan sebagai pengikat pada aroma dan merangsang kemoreseptor sehingga tidak disukai serangga. (Ermaya dkk, 2019). Penelitian ini bertujuan untuk melihat efektifitas repellent dengan kombinasi minyak atsiri serai, daun kemangi, dan nilam terhadap nyamuk Aedes aegypti. Salah satu cara yang mudah dan diaplikasikan adalah dengan bentuk sediaan spray. Spray memiliki keuntungan karena sediaan ini tidak mudah terkontaminasi karena wadah botol tertutup/ kedap udara.

\section{METODE PENELITIAN}

Jenis Penelitian adalah penelitian eksperimen murni(True eksperimen). Penelitian ini menggunakan minyak atsiri serai, daun kemangi, dan nilam. alat-alat gelas, vial, stopwatch, penggaris, labu takar (pyrex), botol semprot, aspirator, sarung tangan, micropippet (soccorex), blue tipe, vortex mixer(VM-300 USA) ,botol vial, meter, magnetic stirer, neraca analitik (Ohaus), pH, piknometer, oven, desikator. Alat yang digunakan untuk uji repellent adalah kandang berukuran 40x40x40cm. Bahan-bahan yang

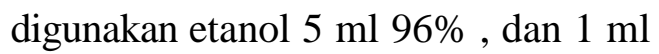
propilen glikol, sebagai pelarut.

Tabel 1. Formulasi spray repellent variasi konsentrasi menggunakan Minyak atsiri Serai, Kemangi dan Nilam

\begin{tabular}{lcccccc}
\hline Bahan/Formula & $\begin{array}{c}\text { Formula } \\
\text { A }\end{array}$ & $\begin{array}{c}\text { Formula } \\
\text { B }\end{array}$ & $\begin{array}{c}\text { Formula } \\
\text { C }\end{array}$ & $\begin{array}{c}\text { Kontrol } \\
(+)\end{array}$ & $\begin{array}{c}\text { Kontrol } \\
(-)\end{array}$ & Keterangan \\
\hline Fraksi Serai & $0,1 \mathrm{ml}$ & $0,2 \mathrm{ml}$ & $0,3 \mathrm{ml}$ & - & DEET & Bahan aktif \\
Fraksi Kemangi & $0,1 \mathrm{ml}$ & $0,2 \mathrm{ml}$ & $0,3 \mathrm{ml}$ & - & - & Bahan aktif \\
Fraksi Nilam & $0,1 \mathrm{ml}$ & $0,2 \mathrm{ml}$ & $0,3 \mathrm{ml}$ & - & - & Bahan aktif \\
Etanol 96\% & $5 \mathrm{ml}$ & $5 \mathrm{ml}$ & $5 \mathrm{ml}$ & $5 \mathrm{ml}$ & - & Pelarut \\
Propilen glikol & $1 \mathrm{ml}$ & $1 \mathrm{ml}$ & $1 \mathrm{ml}$ & $1 \mathrm{ml}$ & - & Pelarut \\
\hline
\end{tabular}

Formulasi spray repellent dibuat dalam gelas kimia dgn mencampurkan bahan aktif dari minyak atsiri (serae, kemangi, nilam) masing- masing konsentrasi $0,1 \mathrm{ml}$ $5 \%), 0,2 \mathrm{ml}(10 \%)$, dan $0,3 \mathrm{ml}(15 \%)$ 
Jurnal Ilmiah Ibnu Sina, 6(1), Maret 2021, 87-97

p-ISSN: 2502-647X; e-ISSN: 2503-1902

kemudian dicampur pelarut etanol menggunakan oven, kemudian bobot 96\% 5ml dan propilen glikol $1 \mathrm{ml}$. piknometer kosong ditimbang $\left(\mathrm{t}=25^{0}\right.$ Untuk jelasnya dapat dilihat pada Tabel 1 .

\section{Evaluasi Sifat Spray}

\section{Uji pH}

Uji $\mathrm{pH}$ dilakukan untuk mengetahui tingkat keasaman dari produk yang dihasilkan. Pengukuran $\mathrm{pH}$ dilakukan dengan menggunakan pH-meter. Sebanyak $5 \mathrm{ml}$ contoh dimasukkan ke dalam gelas piala 100 $\mathrm{ml}$ yang telah berisi $50 \mathrm{ml}$ air suling. Kemudian ditambahkan lagi air suling hingga tepat $100 \mathrm{ml}$ dan diaduk sampai homogen. Selanjutnya $\mathrm{pH}$ larutan diukur dengan menggunakan $\mathrm{pH}$-meter

\section{Pengujian Organoleptik}

Pemeriksaan organoleptik dilakukan dengan cara mengamati tampilan fisik dari sediaan, meliputi bentuk, warna dan bau pada hari ke 0 , 7, 14 dan 21 pada suhu ruang

\section{Bobot Jenis}

Prinsip pengukuran bobot jenis adalah membandingkan bobot contoh terhadap bobot air pada suhu dan volume yang sama. Pengukuran dilakukan dengan menggunakan piknometer. Piknometer $25 \mathrm{ml}$ dicuci terlebih dahulu dan disterilkan dengan

Piknometer diisi dengan air hingga penuh dan ditutup rapat agar tidak terbentuk gelembung udara. Bobot piknometer yang telah berisi air tersebut ditimbang dengan menggunakan neraca analitik semula. Piknometer yang telah kosong diisi lagi dengan larutan sampel anti nyamuk hingga penuh dan ditutup rapat. Bobot piknometer yang berisi sampel antinyamuk kemudian ditimbang.

Bobot jenis dihitung berdasarkan persamaan:

$\mathrm{W}=$ berat piknometer kosong $(\mathrm{g})$

$\mathrm{W} 1=$ bobot piknometer + air $(\mathrm{g})$

$\mathrm{W} 2=$ bobot piknometer + sampel antinyamuk $(\mathrm{g})$

Berat jenis $\left(25^{\circ} \mathrm{C} / 25^{\circ} \mathrm{C}\right)=\frac{W 2-W}{W 1-W}$

\section{Kestabilan Emulsi}

Sejumlah sampel antinyamuk yang sudah ditimbang dimasukkan ke dalam wadah.Wadah dan sampel tersebut dimasukkan ke dalam oven dengan suhu $45^{\circ}$ C.Bobot wadah dan sampel tersebut diamati setiap 15 menit hingga mencapai bobot yang konstan.Setelah bobotnya konstan kemudian diletakkan di dalam desikator hingga dingin dan ditimbang lagi bobot fase akhir yang tersisa. 
Jurnal Ilmiah Ibnu Sina, 6(1), Maret 2021, 87-97

p-ISSN: 2502-647X; e-ISSN: 2503-1902

Kestabilan emulsi dihitung serai,kemangi, nilam masing- masing berdasarkan persamaan

Kestabilan emulsi $(\%)=$

$$
\frac{\text { Bobot Fase yang tersisa }}{\text { Bobot Awal }} \times 100
$$

\section{Patch test}

Uji patch sediaan pada 10 probandus yang di aplikasikan ke kulit selama 15 menit dan di lihat reaksinya terjadi iritasi (tidak) (Yuniarsih,2010)

\section{Uji Preferensi}

Uji kesukaan atau uji hedonik: pada uji ini panelis mengemukakan tanggapan pribadi suka atau tidak suka, disamping itu juga mengemukakan tingkat kesukaannya. Tingkat kesukaan disebut juga skala hedonik. Skala hedonik ditransformasi ke dalam skala numerik dengan angka (5-1) menaik/ menurun tingkat kesukaan. Organoleptik / hedonik dengan memberikan sampel kepada 25. (Setyaningsih, dkk., 2010).

\section{Uji Persentase Daya Proteksi}

Analisis prosentase daya proteksi (PDP) dalam penelitian ini menggunakan Rancangan Acak Lengkap (RAL), terdiri atas lima perlakuan:Kontrol negatif (Kn) konsenterasi $5 \%$ minyak atsiri
0,1 $\mathrm{ml}$ (formula A), konsenterasi $10 \%$ minyak atsiri serai,kemangi, nilam masing- masing 0,2 $\mathrm{ml}$ (formula $\mathrm{B}$ ), konsenterasi $15 \%$ minyak atsiri serae,kemangi, nilam masing- masing $0,3 \mathrm{ml}$ (formula $\mathrm{C}$ ), dan kontrol positif (Kp). Nyamuk (25 ekor) .dengan 10 kali ulangan selama waktu pengamatan 6 jam (0-1jam, 1-2jam, 2-3jam, 3-4jam, 4-5jam, 5-6jam).

Menggunakan rumus :

Keterangan

$$
\operatorname{PDP}(\%)=\frac{C-T}{C} \times 100 \%
$$

PDP: Presentasi daya Proteksi

$\mathrm{C}$ : Jumlah nyamuk yang hinggap pada kontrol negatif

$\mathrm{T}$ : Jumlah nyamuk yang hinggap pada lengan kelompok uji

\section{HASIL DAN PEMBAHASAN}

Uji Daya Proteksi (repellent)

Tempat penelitian uji repellent dilakukan di Fakultas Kesehatan Masyarakat Universitas Ahmad Dahlan. Uji repellent dilakukan sesuai prosedur (Kardinan,2010).Setelah spray dibuat dengan berbagai seri konsentrasi langkah selanjutnya yaitu pengujian dengan cara spray disemprotkan ke punggung tangan probandus yang sebelumnya sudah dicuci dandipastikan tidak ada bau 
Jurnal Ilmiah Ibnu Sina, 6(1), Maret 2021, 87-97

p-ISSN: 2502-647X; e-ISSN: 2503-1902

ditangan.Uji Repellent, uji kontrol negatif dan uji kontrol positif harus diterapkan secara merata di atas permukaan kulit dan total area disekitar lengan dari pergelangan tangan ke siku lengan dan pengukuran keliling pergelangan tangan (B) Siku cubital fossa dan panjang lengan (D).Tangan kemudian dimasukkan ke kotak berisi 25 ekor nyamuk.

Berdasarkan hasil sidik ragam menunjukkan bahwa terjadi pengaruh yang sangat nyata dengan pemberian repellent spray terhadap gigitan nyamuk.

Tabel 2. Rata-Rata Jumlah Gigitan nyamuk pada Berbagai Perlakuan Konsenterasi Sedian Spray pada Jam Pertama sampai Jam ke Enam

\begin{tabular}{lrrrrrr}
\hline \multirow{2}{*}{ Perlakuan } & \multicolumn{6}{c}{ Gigitan Nyamuk pada Waktu Pengamatan (jam) } \\
\cline { 2 - 7 } & $\mathbf{0 - 1}$ jam & $\mathbf{1 - 2}$ jam & $\mathbf{2 - 3}$ jam & $\mathbf{3 - 4}$ jam & $\mathbf{4 - 5}$ jam & $\mathbf{5 - 6}$ jam \\
\hline Kontrol (-) & $17,80^{\mathrm{a}}$ & $17,30^{\mathrm{a}}$ & $16,50^{\mathrm{a}}$ & $15,50^{\mathrm{a}}$ & $14,20^{\mathrm{a}}$ & $13,30^{\mathrm{a}}$ \\
Kontrol (+) & $0,40^{\mathrm{a}}$ & $0,60^{\mathrm{d}}$ & $0,70^{\mathrm{d}}$ & $0,70^{\mathrm{d}}$ & $0,80^{\mathrm{d}}$ & $0,90^{\mathrm{d}}$ \\
Konsentrasi 5\% & $3,20^{\mathrm{b}}$ & $3,70^{\mathrm{b}}$ & $4,10^{\mathrm{b}}$ & $4,90^{\mathrm{b}}$ & $5,70^{\mathrm{b}}$ & $6,90^{\mathrm{b}}$ \\
Konsentrasi 10\% & $2,40^{\mathrm{c}}$ & $3,00^{\mathrm{c}}$ & $3,50^{\mathrm{c}}$ & $3,90^{\mathrm{c}}$ & $4,80^{\mathrm{c}}$ & $5,70^{\mathrm{c}}$ \\
Konsentrasi 15\% & $1,80^{\mathrm{d}}$ & $2,50^{\mathrm{c}}$ & $2,90^{\mathrm{c}}$ & $3,60^{\mathrm{c}}$ & $4,50^{\mathrm{d}}$ & $5,40^{\mathrm{c}}$ \\
\hline BNJ 5\% & 0,5323 & 0,5885 & 0,5544 & 0.6144 & 0,651 & 0,6083 \\
\multicolumn{1}{c}{ 1\% } & 0,7122 & 0,7874 & 0,7417 & 0,8220 & 0,872 & 0,8140 \\
\hline
\end{tabular}

Keterangan: Angka yang dikuti huruf yang sama pada kolom yang sama menunjukkan tidak berbeda nyata pada uji BNT $\alpha=0,05$

Selanjutnya untuk menentukan persentase daya proteksi dari masingmasing perlakuan maka akan diuji atau dihitung Presentase Daya Proteksinya. Adapun hasil perhitungan Persentase Daya Proteksinya (PDP) dapat dilihat pada Tabel 2.

Hasil PDP (\%) dari seluruh perlakuan sedian pada Tabel 2 . menunjukkan bahwa ada kecenderung semakin lama waktu pengamatannya, maka semakin menurun persentase daya proteksinya. Walaupun penurunannya hanya mulai dari waktu pertama pemberian perlakuan dan pengamatan sampai pada waktu pengamatan ke 3-4 jam, karena pada waktu 4-5 dan 5-6 terjadi penaikan kembali persentase daya proteksi dari semua perlakuan. Dari rata- rata persentase daya proteksi dari waktu ke waktu, dimana pada waktu pengamatan pertama (0-1 jam) itu persentasenya $89,03 \%$, waktu pengamatan (1-2jam) turun $85,84 \%$, 
Jurnal Ilmiah Ibnu Sina, 6(1), Maret 2021, 87-97

p-ISSN: 2502-647X; e-ISSN: 2503-1902

waktu pengamatan (2-3jam) turun $83,04 \%$, dan waktu pengamatan (3-4 jam) turun $78,87 \%$. Kemudian setelah itu terjadi kenaikan menjadi $85.57 \%$ (4-5jam) dan $84.4 \%$ pada (5-6jam). pH

Uji pH dilakukan untuk mengetahui tingkat keasaman dari produk yang dihasilkan. Produk yang memiliki $\mathrm{pH}$ yang terlalu tinggi atau terlalu rendah akan mempengaruhi tidak terhadap permukaan, misalnya akan mengalami iritasi. Menurut Wasiatatmaja (1997) $\mathrm{pH}$ untuk setiap produk yang akan digunakan pada kulit manusia, sebaiknya pHnya disesuaikan dengan pH kulit yaitu sebesar 4,5 - 7,0.

Menunjukkan bahwa hasil pengukuran $\mathrm{pH}$ sedian yang merupakan campuran minyak atsiri ( serai : kemangi : nilam) yang konsenterasinya $5 \% \quad \mathrm{pH} \quad(4.92)$ (asam), dan sedian yang konsenterasinya $10 \% \mathrm{pH}$ nya (6.24) (asam) serta konsentrasi sediaan 15\% adalah sebesar $\mathrm{pH} 4.64$ (asam). Ini menunjukkan bahwa $\mathrm{pH}$ sedian yang dihasilkan Tabel 3. sangat sesuai dengan $\mathrm{pH}$ kulit ( $\mathrm{pH} 4,5-7,0$ ), begitu juga soffel spray sebagai kontrol positif yang memiliki $\mathrm{pH} \quad 4,73$.
Dengan kata lain jika digunakan pada kulit manusia tidak akan mengalami iritasi.

Tabel 3. Hasil Pengukuran $\mathrm{pH}$ sedian konsenterasi 5\%, 10\%, 15\%

\begin{tabular}{cccc}
\hline No. & Formula & pH & Keterangan \\
\hline 1. & I & 4.92 & Asam \\
2. & II & 6.24 & Asam \\
3. & III & 4.64 & Asam \\
\hline
\end{tabular}

Keterangan:

Formula I= Konsenterasi 5\%

Formula II= Konsenterasi $10 \%$

Formula III= Konsenterasi $15 \%$

\section{Uji Organoleptik}

Uji Organoleptik merupakan salah satu kontrol kualitas untuk spesifikasi produk jadi sediaan spray. Parameter yang diuji meliputi warna, bau, dan tekstur. Sifat organoleptis berpengaruh pada estetika dan kenyamanan pada saat pemakaian. Sediaan yang memiliki warna dan bau yang menyenangkan akan lebih diterima dan disukai oleh pemakai. Tekstur spray yang tidak terlalu cair akan memudahkan pemakaiannya pada kulit.

Pengamatan organoleptik dilakukan selama 21 hari penyimpanan pada suhu ruang (25$26^{\circ} \mathrm{C}$ ) dan diamati perubahannya pada hari ke-0, ke-7, ke-14, dan ke-21, untuk mengetahui stabilitas sediaan spray. Pada hari ke-0 dilakukan 
Jurnal Ilmiah Ibnu Sina, 6(1), Maret 2021, 87-97

p-ISSN: 2502-647X; e-ISSN: 2503-1902

pengamatan sediaan spray minyak atsiri (serai,kemangi dan nilam) memiliki warna putih pucat, bau khas minyak atsiri, memiliki tekstur yang cair berminyak, dan tidak terasa lengket.

Pada suhu penyimpanan 25$26^{\circ} \mathrm{C}$ pada gelas menunjukkan adanya perbedaan warna pada sediaan spray karena perbedaan konsenterasi minyak atsiri. Semakin tinggi konsenterasi minyak atsiri, menyebabkan warna sedian semakin kuning. Warna kuning itu disebabkan oleh adanya reaksi antara minyak atsiri serai, kemangi dan nilam.

Setelah penyimpanan ke-21 hari pada pengemas botol mengalami perubahan ditandai dengan adanya endapan pada dasar botol, hal ini menunjukkan adanya ketidakstabilan pada sediaan spray, yang menyebabkan semua atau sebagian dari cairan fase dalam tidak teremulsikan dan membentuk suatu lapisan yang berbeda pada pada dasar kemasan botol sedian spray yang sangat dipengaruhi oleh perubahan fisika dan kimia lain (Ansel, 1989). Jika sedian spray tersebut dikocok kembali, maka akan endapan tersebut hilang.

Bobot jenis adalah salah satu syarat mutu yang menjadi pembuatan spray repellent. Prinsip pengukuran bobot jenis adalah membandingkan bobot contoh terhadap bobot air pada suhu dan volume yang sama. Pengukuran dilakukan dengan menggunakan piknometer.

Hasil pengukuran atau perhitungan bobot jenis dari sedian yang diteliti menunjukkan bahwa bobot jenis (BJ) sedian $5 \%$ (Formula I ) sebesar 1,08, dan bobot jenis (BJ) sedian $10 \%$ (Formula II) sebesar 1,09, serta bobot jenis (BJ) sedian $15 \%$ (Formula III) sebesar 1,10.

\section{Kestabilan Emulsi}

Uji kestabilan emulsi sedian adalah suatu cara/metode untuk mengukur suatu sedian apakah stabil atau tidak, karena setiap sistim itu tidak stabil karena masing- masing partikel mempunyai kecenderungan untuk bergabung dengan partikel lainnya (Suryani et all, 2000). Persentase kestabilan emulsi yang didapatkan dalam penelitian ini memiliki nilai hampir $100 \%$ yaitu masing-masing 99,1\% (formola 1), 98,57\% (Formula 
Jurnal Ilmiah Ibnu Sina, 6(1), Maret 2021, 87-97

p-ISSN: 2502-647X; e-ISSN: 2503-1902

2) dan 99,93\% (Formula 3). Hal ini dengan baik (Prasetyo, 2011). Untuk menunjukkan bahwa semua formula lebih dapat dilihat pada Tabel 6 .

yang terbentuk sudah tercampur

Tabel 4. Hasil pengamatan organoleptis masing masing sediaan

\begin{tabular}{lllll}
\hline \multicolumn{2}{c}{ Konsentrasi } & Formula 0,1 (5\%) & \multicolumn{1}{c}{$\begin{array}{c}\text { Formula 0,2 } \\
(\mathbf{1 0 \% )}\end{array}$} & $\begin{array}{c}\text { Formula 0,3 } \\
(\mathbf{1 5 \% )}\end{array}$ \\
\hline \multirow{3}{*}{ Hari pertama } & Bentuk & Cair berminyak & Cair berminyak & Cair berminyak \\
& Warna & Hampir jernih & Agak kuning & Lebih kekuningan \\
& Bau & Khas minyak atsiri & Khas minyak atsiri & Khas minyak atsiri \\
\hline \multirow{3}{*}{ Hari ke-7 } & Bentuk & Cair berminyak & Cair berminyak & Cair berminyak \\
& Warna & Hampir jernih & Agak kuning & Lebih kekuningan \\
& Bau & Khas minyak atsiri & Khas minyak atsiri & Khas minyak atsiri \\
\hline \multirow{3}{*}{ Hari ke-14 } & Bentuk & Cair berminyak & Cair berminyak & Cair berminyak \\
& Warna & Hampir jernih & Agak kuning & Lebih kekuningan \\
& Bau & Khas minyak atsiri & Khas minyak atsiri & Khas minyak atsiri \\
\hline \multirow{3}{*}{ Hari ke-21 } & Bentuk & Endapan kuning & Endapan kuning & Endapan kuning \\
& Warna & Hampir jernih & Agak kuning & Lebih kekuningan \\
& Bau & Khas minyak atsiri & Khas minyak atsiri & Khas minyak atsiri \\
\hline
\end{tabular}

Tabel 5. Hasil pengamatan kestabilan emulsi masing masing sediaan

\begin{tabular}{cccccc}
\hline \multirow{2}{*}{ Formula } & \multicolumn{5}{c}{ Kestabilan Emulsi } \\
\cline { 2 - 6 } & $\begin{array}{c}\text { Bobot Botol } \\
\text { kering } \\
\text { (kosong) }\end{array}$ & $\begin{array}{c}\text { Bobot Botol } \\
+ \text { anti } \\
\text { nyamuk }\end{array}$ & $\begin{array}{c}\text { Bobot Awal } \\
\text { sediaan }\end{array}$ & $\begin{array}{c}\text { Botol sedia } \\
\text { yang tersisa }\end{array}$ & $\begin{array}{c}\text { Kestabilan } \\
\text { emulsinya } \\
(\boldsymbol{\%})\end{array}$ \\
\hline 0,1 & 10,925 & 15,124 & 4,199 & 4,195 & 99,91 \\
0,2 & 10,864 & 14,929 & 4,118 & 4,059 & 98,57 \\
0,3 & 10,839 & 14,957 & 4,118 & 4,115 & 99,93 \\
\hline
\end{tabular}

\section{Bobot Jenis}

Tabel 6. Hasil pengamatan bobot jenis masing masing sediaan

\begin{tabular}{ccccc}
\hline \multirow{2}{*}{ Formula } & \multicolumn{4}{c}{ Bobot Jenis g/ml } \\
\cline { 2 - 5 } & $\begin{array}{c}\text { Bobot piknometer } \\
\text { kosong (g) }\end{array}$ & $\begin{array}{c}\text { Bobot piknometer }+ \\
\text { air (g) }\end{array}$ & $\begin{array}{c}\text { Bobot piknometer + } \\
\text { Formula (g) }\end{array}$ & $\begin{array}{c}\text { BJ } \\
\text { sediaan }\end{array}$ \\
\hline 0,1 & 30,46 & 38,16 & 38,84 & 1,08 \\
0,2 & 30,46 & 38,16 & 38,86 & 1,09 \\
0,3 & 30,46 & 38,16 & 38,95 & 1,10 \\
\hline
\end{tabular}

Hasil kestabilan emulsi dari konsenterasi sedian $15 \%$ (Formula sedian, menunjukkan bahwa 0.3) adalah 14,954\% Tabel 7.

kestabilan emulsi sedian pada Patch Test

konsenterasi $5 \%$ (Formula 0.1) pada

$15,120 \%$, dan konsenterasi sedian 10

$\%$ (Formula 0.2) pada $14,923 \%$, serta
Uji keamanan sediaan dengan 10probandus yang di aplikasikan ke kulit selama 15 menit kemudian di lihat reaksinya terjadi iritasi/ alergi atau 
Jurnal Ilmiah Ibnu Sina, 6(1), Maret 2021, 87-97

p-ISSN: 2502-647X; e-ISSN: 2503-1902

tidak (Yuniarsih,2010). Jika terjadi keamanan (patch test) dilakukan reaksi pada kulit probandus, itu berarti dengan menyemprotkan sedian spray kurang baik untuk digunakan atau pada bagian lengan atas 10 probandus. dipakaikan pada kulit orang. Uji

Tabel 7. Hasil pengamatan kestabilan emulsi masing masing sediaan

\begin{tabular}{cccccc}
\hline & \multicolumn{4}{c}{ Bobot Jenis g/ml } \\
\cline { 2 - 6 } Formula & $\begin{array}{c}\text { Bobot Botol kering } \\
\text { (kosong) }\end{array}$ & $\begin{array}{c}\text { Bobot Botol + anti } \\
\text { nyamuk }\end{array}$ & $\begin{array}{c}\text { Bobot Awal } \\
\text { sediaan }\end{array}$ & $\begin{array}{c}\text { Bobot } \\
\text { sedia } \\
\text { yang } \\
\text { tersisa }\end{array}$ & $\begin{array}{c}\text { Kestabilan } \\
\text { emulsinya } \\
(\%)\end{array}$ \\
\hline 0,1 & 10,925 & 15,124 & 4,199 & 4,195 & 99,91 \\
0,2 & 10,864 & 14,929 & 4,119 & 4,059 & 98,57 \\
0,3 & 10,839 & 14,957 & 4,188 & 4,115 & 99,93 \\
\hline
\end{tabular}

Tabel 8. Hasil Pengamatan Patch Test

\begin{tabular}{cccc}
\hline \multirow{2}{*}{ Jenis Iritasi } & \multicolumn{3}{c}{ Hari ke - } \\
\cline { 2 - 4 } & $\mathbf{1}$ & $\mathbf{2}$ & $\mathbf{3}$ \\
\hline Rasa Gatal & $\mathrm{X}$ & $\mathrm{X}$ & $\mathrm{X}$ \\
Kemerahan & $\mathrm{X}$ & $\mathrm{X}$ & $\mathrm{X}$ \\
Kulit Bengkak & $\mathrm{X}$ & $\mathrm{X}$ & $\mathrm{X}$ \\
Rasa Perih & $\mathrm{X}$ & $\mathrm{X}$ & $\mathrm{X}$ \\
\hline Keteran
\end{tabular}

Keterangan $\mathrm{X}$ : tidak ditemukan jenis iritasi pada 10 probandus

Hasil patch test dari 10 probandus, selama tiga hari berturutturut tidak mengalami gejala iritasi seperti rasa gatal, kemerahan, kulit bengkak, dan rasa perih dibagian kulit. Hal ini sesuai dengan pendapat Wasiatmaja (1997) bahwa produk yang pHnya sesuai dengan $\mathrm{pH}$ kulit manusia, maka produk itu aman bagi kulit manusia atau tidak akan membuat gejala iritasi pada kulit.

\section{Preferensi}

Uji kesukaan atau uji hedonik: pada uji ini panelis mengemukakan tanggapan pribadi suka atau tidak suka, disamping itu juga mengemukakan tingkat kesukaannya. Tingkat kesukaan disebut juga skala hedonik. Skala hedonik ditransformasi ke dalam skala numerik dengan angka menaik/ menurun tingkat kesukaan. Adapun nilai skala numeriknya adalah sebagai berikut:sangat suka (SS) nilai 5, suka (S) nilai 4, Biasa (B)nilai 3, kurang suka (KS)nilai 2, dan tidak suka (TS) nilai 1. Organoleptik/ hedonik dengan memberikan sampelkepada 25 panelis kriteria yang diujikan yaitu penampilan fisik, warna, aroma, tekstur. .(Setyaningsih, dkk., 2010).

Dari hasil uji hedonik sedian dari hasil penelitian dengan di perlihatkan/ditanyakan pada pada 25 
Jurnal Ilmiah Ibnu Sina, 6(1), Maret 2021, 87-97

p-ISSN: 2502-647X; e-ISSN: 2503-1902

panelis (25 probandus), ternyata dari 25 panelis lebih banyak menyukai hasil sedian spray yang konsenterasi $10 \%$ atau formula 0.2 , yaitu : untuk warnanya bernilai 78 ,bentuk/tekstur bernilai 79 dan aroma/bau bernilai 84 .

\section{KESIMPULAN}

Repellent dengan bahan aktif alami yang berasal dari minyak atsiri bisa menjadi salah satu alternatif karena dapat berdampak positif bagi lingkungan di banding dengan insektisida kimia yang mengandung senyawa DEET.

1. Analisis uji kualitas pada sediaan yang berbahan dasar alami pada penilitian memiliki kualitas yang baik. Baik dilihat dari pHnya (4,64- 6,24), patch test tidak ada mengalami iritasi selama pengujian 3 hari, kestabilan emulsi $(98,57 \%$ 99,93\%) hampir mendekati $100 \%$, bobot jenis sedian $(1,088 \mathrm{~g} / \mathrm{ml}$ $1,103 \mathrm{~g} / \mathrm{ml}$ ), uji preferensi warna, bentuk dan aroma sediaan bernilai 66- 84

2. Dari semua perlakuan replen spray yang minyak atsirih sebagai bahan aktifnya, menujukkan bahwa formula B (konsenterasi 10\%) lebih baik dan efektif untuk mencegah nyamuk, dilihat dari jumlah gigitan nyamuk dan PDP.

\section{DAFTAR PUSTAKA}

Irwan.,2019, Epidemiologi Penyakit Menular. Page 106-107, Absoulute Media.Yogyakarta

Kardinan, Agus., dan Dhalimi Azmi. 2010. Potensi Adas (Foeniculum vulgare) Sebagai Lotion Anti Nyamuk Aedes aegypti. Bul. Littro. Vol. 21, No. 1, Hal 61- 68.

Prasetyo (2011) Formulasi Anti Nyamuk Spray Menggunakan Bahan AKtif Minyak Nilam

Setyaningsih, Dwi, Anton Apriyantono, dan Maya Puspita Sari. (2010). Analisis Sensori untuk Industri Pangan dan Argo. Bogor: IPB Press

Sulaswatty,A.,Rusli,M.S.,Abimanyu., H.,Tursiloadi (2019) Quo vadis minyak sereh wangi dan turunanya.Jakarta:LIPI Press

Yuniarsih,E. 2010. Uji efektivitas losion repellent minyak nimba (Azadirachta indica A. Juss) terhadap nyamuk Aedes aegypti. Skripsi.Universitas Islam Negeri (UIN) syarif Hidayatullah,Jakarta.

Wasiaatmaadja,S.M. 1997 Penuntun Ilmu Kosemetik Medik. Jakarta: Universitas Indonesia Press 